BLS 35, No 1 2009. DOI: http://dx.doi.org/10.3765/bls.v35i1.3629

(published by the Berkeley Linguistics Society and the Linguistic Society of America)

\title{
Bipolar Items and Attitude Predicates
}

\author{
SUMIYO NISHIGUCHI \\ Osaka University
}

\section{Introduction}

This paper discusses bipolar items (BPIs) which share the features of negative polarity items (NPIs) as well as positive polarity items (PPIs). I will argue that both overt and covert factive emotives license BPIs. The Dutch ooit 'ever,' SerboCroatian $i$-series 'and/even,' and Hungarian is-series 'and/even' are anti-licensed by clausemate negation and licensed by extra-clausal negation (van der Wouden 1997, Progovac 1994, Szabolcsi 2002) or non-monotonic negative (and positive, for Serbo-Croatian) emotives. I maintain that the Japanese sentence focus mo 'also/even,' Korean wide-scope to 'also/even,' and Chinese ye 'also' in simple sentences are BPIs licensed by covert emotives. BPIs check their bipolar features with weak or medium negation but cannot check them with strong negation. Adding an NPI rescues BPIs in uncomfortable clausemate negation.

\section{Bipolar Items}

Two kinds of polarity items have been widely discussed so far: negative polarity items (NPIs) and positive polarity items (PPIs). This article focuses on another kind of rarely discussed polarity items, which van der Wouden (1997) called bipolar items (BPIs). These items show NPI and PPI features.

It is well known that NPIs are licensed in the scope of downward entailing (DE) environments (Fauconnier 1975a, Fauconnier 1975b, Ladusaw 1979). ${ }^{1}$ For example, in (1a), the NPI budge an inch is licensed by not, which is strongly negative, because the omission of not makes it ungrammatical (1b). On the contrary, in (2), PPIs such as already are anti-licensed in a negative environment (Baker 1970).

${ }^{1}$ For example, the NPI any is licensed in the scope of the downward entailing operator no fisherman. No itself is also a downward entailing operator:

(i) a. No fisherman caught any fish. $\mid=$ No fisherman caught any sillaginoid.

b. No fisherman caught any sillaginoid. $\mid \neq$ No fisherman caught any fish.

(ii) a. No fisherman caught fish. $\mid=$ No Sunday fisherman caught fish.

b. No Sunday fisherman caught fish. $\mid \neq$ No fisherman caught fish. 


\section{Bipolar Items and Attitude Predicates}

(1) a. John did not budge an inch.

b. *John budged an inch.

(2) a. Simon has already arrived.

b. *Simon has not already arrived.

With respect to BPIs, the Dutch ooit 'ever,' Serbo-Croatian $i$-series 'also/even,' and Hungarian is-series 'and/even' demonstrate NPI-hood by being licensed in medium and weak negative environments but demonstrate PPI-hood when anti-licensed by strong clausemate negation (Szabolcsi p.c., van der Wouden 1997, Progovac 1994, Szabolcsi 2002). ${ }^{2}$

The Dutch ooit 'ever' requires weak or medium negativity but dislikes antimorphic environments in (3). Ooit is licensed by extra-clausal negation in (4). ${ }^{3}$

${ }^{2}$ The classification of negative environments as strong, medium and weak originates in Zwarts (1996, 1997). Anti-morphic determiners or noun phrases are strongly negative, anti-additive or anti-multiplicative expressions are medium negative, and monotone decreasing scope is weakly negative. Anti-morphism is De Morgan negation, which is a combination of anti-additivity and anti-multiplicativity.

(iii) Monotone decreasingness:

Let $\mathrm{B}$ be a Boolean algebra. A quantifier $\mathrm{Q}$ on $\mathrm{B}$ is said to be monotone decreasing iff for each two elements $X$ and $Y$ of the algebra $B$ : if $X \in Q$ and $Y \subseteq X$, then $Y \in Q$.

(iv) Anti-additivity:

Let $\mathrm{B}$ and $\mathrm{B}^{*}$ be two Boolean algebras. A function $\mathrm{f}$ from $\mathrm{B}$ to $\mathrm{B}^{*}$ is said to be anti-

additive iff for each two elements $X$ and $Y$ of the algebra $B$ : $f(X \cup Y)=f(X) \cap f(Y)$

(v) Anti-multiplicativity:

Let $\mathrm{B}$ and $\mathrm{B}^{*}$ be two Boolean algebras. A function $\mathrm{f}$ from $\mathrm{B}$ to $\mathrm{B}^{*}$ is said to be antimultiplicative iff for each two elements $X$ and $Y$ of the algebra $B: f(X \cap Y)=f(X) \cup f(Y)$

(Zwarts 1996)

${ }^{3}$ Hoeksema (1998) discusses the current loss of polarity sensitivity of ooit. According to his observations, ooit has become ambiguous between the NPI ooit and the non-sensitive ooit, which is also used as an existential temporal adverb, nowadays. The latter appears in non-negative contexts.

a. Jan heeft het ooit geweten. Jan has it once known

'Jan once knew it.'

b. Hier stond ooit een molen.

here stood once a mill

'A mill stood here, once.'

Jack Hoeksema also pointed out, at the Swarthmore Workshop on Negation and Polarity in 2006, that it is the Blocking Effect (Aronoff 1976) that makes ooit ungrammatical in a strong negative context. The presence of another lexical item nooit blocks ooit from a strong negative context. However, van der Wouden (1997) argues that ooit also dislikes anti-morphic operators other than niet:

a. *Een van de kinderen gaat allesbehalve ooit bij oma op bezoek. One of the children goes anything-but ever with granny on visit

b. *Een van de kinderen gaat allerminst ooit bij oma op bezoek. One of the children goes not at all ever with granny on visit 


\section{Sumiyo Nishiguchi}

(3) a. Geen van de kinderen gaat ooit bij oma op bezoek. none of the children goes ever with granny on visit 'None of the children ever visits granny.'

(Anti-additive)

b. Weinig kinderen gaan ooit bij oma op bezoek. few children go ever with granny on visit 'Few children ever visit granny.'

(Monotone decreasing)

c. *Een van de kinderen gaat niet ooit bij oma op bezoek. one of the children goes not ever with granny on visit

(Anti-morphic; van der Wouden 1997:132-133)

(4) Het is niet zo dat een van de kinderen ooit bij oma op bezoek gaat. it is not so that one of the children ever with granny on visit goes 'It is not the case that one of the children ever visits granny.'

(van der Wouden 1997:133)

Similarly, the Hungarian is-series and Serbo-Croatian $i$-NPIs are ungrammatical with clausemate anti-morphic negation (5a) but grammatical in monotone decreasing contexts $(5 b)$ or with extra-clausal negation $(5 c)$.

a. *Nem értettél valamit is. not understood-you something also/even 'You didn't understand anything.'

(Hungarian, anti-morphic)

b. Kevés ember értett valamit is. few people understood something also/even 'Few people understood anything.'

(Monotone decreasing)

c. Nem hiszem, hogy valamit is értettél. not think-I that something also/even understood-you 'I don't think that you understood anything.'

(Extra-clausal anti-morphic, Szabolcsi p.c.)

Thus, BPIs dislike clausemate negation and demand either weak or medium negative contexts or extra-clausal negation.

\section{Non-Monotonic Emotives as BPI Licensers}

Licensers of BPIs are not limited to extra-clausal negation or clausemate medium or weak negation: negative emotives license BPIs in (6). The Serbo-Croatian data in (7) indicates that not only negative but also positive attitude predicates license BPIs. 


\section{Bipolar Items and Attitude Predicates}

(6) a. Ik betreur (het) dat ik dat ooit gedaen heb.

I regret it that I that ever done have

'I regret of what I have ever done.'

(Dutch, den Dikken p.c.)

b. Sajnálom, hogy valamit is adtam neki.

regret-I that something-ACC also/even gave-I to-him

'I regret that I gave him anything.'

(Hungarian, Szabolcsi p.c.)

(7) a. Sumnja-m da Milan voli i(t)ko-ga/*ni(t)ko-ga.

doubt-1SG that Milan loves anyone-ACC/ no-one-ACC

'I doubt that Milan loves anyone.'

(Progovac 1994:64)

b. Sretan sam da Milan i(t)ko-ga voli.

happy be.1SG that Milan anyone-ACC loves

'I am happy that Milan loves anyone.'

The monotonicity of emotives such as doubt, be happy, be surprised, and regret has posed a problem in Fauconnier-Ladusaw's DE analysis of NPI licensing contexts, because these attitude predicates are not straightforward DE (Asher 1987, Heim 1992, von Fintel 1999). For instance, I am happy that Mary bought a car does not imply I am happy that Mary bought a Honda, since the car Mary bought could be a Toyota. Similarly, the latter does not imply the former, for the speaker could be happy about the Honda and not necessarily glad that Mary spent money on a new car.

(8) I am happy that Mary bought a car. $<=/=>$

I am happy that Mary bought a Honda.

Without additional devices such as weakened DE (Asher 1987) or Strawson DEness (von Fintel 1999), attitude predicates are non-monotonic. Both weakened DE and Strawson Entailment add additional assumptions such that the complement clause of the conclusion is also believed.

(9) I am happy that Mary bought a car.

Mary bought a Honda.

$\therefore$ I am happy that Mary bought a Honda

Thus far, we have seen that BPIs dislike clausemate negation and demand weak or medium negative contexts, extra-clausal negation, or superordinate emotives. While Dutch and Hungarian BPIs are only licensed by negative emotives, Serbo-Croatian BPIs can be licensed by positive emotives. Considering the 


\section{Sumiyo Nishiguchi}

attitude predicates to be non-monotonic, BPI licensing contexts range from nonmonotonic to monotone decreasing and anti-additive environments.

\section{Implicit Non-Monotonic Emotives License BPIs}

This section argues that not only overt emotives such as regret or be sorry but also covert emotives license BPIs. The Japanese mo 'also/even,' Korean to 'also/even' and Mandarin ye 'also' behave as BPIs when anti-licensed by clausemate negation or licensed in monotone decreasing contexts. Crucially, these BPIs can be licensed by implicit speaker attitudes.

\subsection{Sentence Focus mo 'also/even' in Japanese}

The Japanese additive mo 'also/even' usually requires an explicit antecedent, as does the English additive also/too; for example, John is the antecedent of Mary in John came, and Mary came too (see (10) for the same example in Japanese). 'Even' appears when mo 'also/even' attaches to a noun phrase that refers to a scalar endpoint; for instance, in (11), John is the least likely person to come.

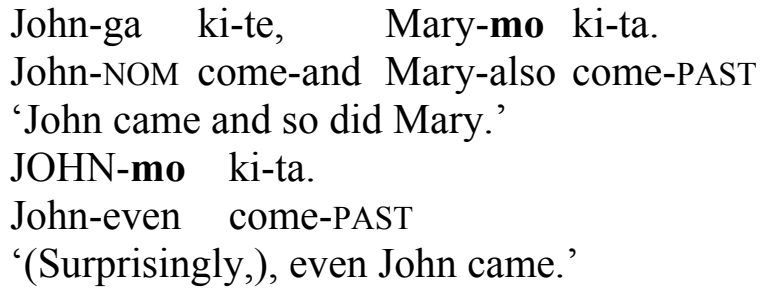

When $m o$ attaches to $w h$-words, it forms any-type strong NPIs (Kato 1985, Nam 1994, Kato 2000) or negative concord items (Watanabe 2004). ${ }^{4}$

There is a third kind of mo 'also/even,' which has, so far, not been discussed much. Numata (2000) claims that this mo 'also/even' takes a wide scope over a proposition and triggers presupposed implicit events. I characterize it as a discourse initial mo or a propositional attitude mo, which can appear discourse initially, out of the blue, and does not require a discourse antecedent. Instead, this mo requires certain speaker attitudes:
a. Yo-mo fukete-ki-ta. Mo neru-to shi-yo. ${ }^{5}$ night-also late-become-PAST already sleep-COMP do-will 'It's become late (at night). It's time to go to bed.'
b. Shikuramen-mo karete-ki-ta. Mo haru-da. cyclamen-also wither-come-past now spring-be 'The cyclamens have withered. Spring is already here.'

\footnotetext{
${ }^{4}$ Japanese grammarians have considered mo polysemous (Sadanobu 1997).

${ }^{5}$ Modified from Sadanobu (1997). I am grateful to Norihiro Ogata for suggesting this example.
} 
c. Ko-no saifu-mo furuku-nat-ta. this-GEN wallet-also old-become-PAST

'This wallet has become old.'

d. Mari-mo kashiko-i.

Mari-also smart-be

'Mary is indeed smart.'

e. Soto-mo hiete-ki-ta. outside-also cold-ASP-PAST

'It has become cold outside.'

f. Tabi-mo owari-ni chikazuite-ki-ta.

trip-also end-to approach-ASP-PAST

'The trip is coming to an end.'

g. Omae-mo aho-ya-na.

you-also silly-be-EXC

'You are indeed silly.'

This mo has sentence-focus structures in the sense of Lambrecht (1994). As an answer to the question what happened, the entire proposition my car broke down is new information and is therefore focused on.
a. What happened? My CAR broke down.
b. Presupposition:
c. Assertion: 'speaker's car broke down'
d. Focus domain: 'speaker's car broke down'
e. Focus: $\mathrm{S}$

(Lambrecht 1994:233)

The discourse-initial mo is a BPI which shows PPI-hood when anti-licensed by clausemate negation, as in (14a) and (15a). Moreover, extra-clausal strong negation, (14b) and (15b); monotone decreasing numeral, at most $n$ (16); and nonmonotonic emotives can be its licensers (17).

a. *Yo-mo sue-ja-nai. world-also end-be-NEG 'This is not the end of the world.'

b. Yo-mo sue-da-to-iu-koto-wa-nai. world-also end-be-COMP-say-fact-TOP-NEG 'It is not true that this is the end of the world.'

a. *Tabi-mo owari-ni chikazuite-ko-nai. trip-also end-DAT approach-ASP-NEG 'The trip is not drawing to an end.' 


\section{Sumiyo Nishiguchi}

b. Tabi-mo owari-ni chikazuite-ki-ta wake demo-nai.

trip-also end-DAT approach-ASP-PAST reason be-NEG

'It is not that the trip is drawing to an end.'

(16) Seizei 5-nin-no gakusei-mo tsukare-ta.

at most 5-CL-GEN student-also tired-PAST

'At most five students grew tired.'
a. Yo-mo fukete-ki-te
zannen-da.
night-also late-become-PAST.and regretful-be
'I am sorry that it got late (at night).'
b. Shikuramen-mo karete-ki-te
kanashii.
cyclamen-also wither-come-PAST.and sad
'I am sad the cyclamens have withered.'

Even though the typical $m o$-sentences of this sort are simple declarative sentences, the speaker's sentimental emotions, either negative or positive, is indispensable:

a. (Zannenna-koto-ni) yo-mo fukete-ki-ta. regretful-fact-GOAL night-also late-become-PAST

'(I am sorry that) it's become late (at night).'

b. (Shimijimi-to) Ko-no saifu-mo furuku-nat-ta. heartily-COMP this-GEN wallet-also old-become PAST '(Heartily) This wallet has become old.'

(19) (Ureshii-koto-ni) haru-mo takenawa-ni nari-mashi-ta. ${ }^{6}$ (happy-fact-GOAL) spring-also peak-GOAL become-HON-PAST '(I'm glad that) spring has reached its peak.'

Therefore, the BPI licensing environments in Japanese are: (i) downward entailing scope, (ii) extra-clausal antimorphic negation, (iii) extra-clausal nonmonotonic emotives, and (iv) covert superordinate emotives. Covert superordinate emotives are peculiar to Japanese as well as to Korean and Chinese BPIs.

\subsection{Korean to 'also/even'}

The Korean to 'also/even' follows the same pattern as the Japanese BPI mo. The sentence focus to 'also/even' is triggered by implicit emotions such as be sad or regret when anti-licensed by clausemate negation. ${ }^{7}$

a. Pom-to wat-ta. spring-also come-PAST

'Spring has come.' (That's why I'm so sad.)

\footnotetext{
${ }^{6}$ The body of this sentence is taken from Numata (2000), even though Numata does not discuss speaker attitudes toward the propositions.

${ }^{7}$ My thanks to Hejeong Ko for providing the Korean examples.
} 


\title{
Bipolar Items and Attitude Predicates
}

\author{
b. \#Pom-to ogi anat-ta. \\ spring-also come NEG-PAST \\ 'Spring has not come.' (That's why I'm so sad.)
}

\subsection{Chinese ye 'also'}

Sentence focus ye 'also' in Mandarin Chinese is also a BPI, for it is licensed by speaker feelings, as in (21a); however, clausemate negation interferes with it in (21b) ${ }^{8}$ Clausemate negation does not interfere with ye 'also' as shown in $(21 \mathrm{c})$ :
a. Qiutian ye lai-le.
fall also come-PERF
(In view of the foregoing events) 'Fall has come.'
b. \#Qiutian ye bu lai-le.
fall also NEG come-PERF
'Fall is not here.'
c. Lingling bu lai-le. Shu ye bu lai-le.
Lingling NEG come-PERF Shu also NEG come-PERF
'Lingling did not come. Neither did Shu.'

The monotone decreasing operator at most licenses the BPI ye 'also' in (22), as do non-monotonic emotives in (23).

(22) Zhangsan zuiduo ye zhi neng he san bei jiu.

Zhangsan at most also only can drink three glass liquor

'Zhangsan can drink three glasses of liquor at the most (it's a pity).'
a. Keqi qiutian ye likai-le. sorry fall also leave-PERF 'I'm sorry that fall is over.'
b. Xinhao qiutian ye likai-le. glad fall also leave-PERF 'I'm glad that fall is over.'

\section{Modal-like Elements or an NPI Rescues BPIs with Negation}

The insertion of an NPI rescues BPIs in otherwise uncomfortable anti-morphic environments, as in (24). ${ }^{10}$ Moreover, (25) indicates that the presence of a modallike element also rescues otherwise uncomfortable BPIs under negation. ${ }^{11}$

\footnotetext{
${ }^{8}$ I owe most of the following Mandarin examples to Chih-hsiang Shu.

${ }^{9}$ My thanks to Pei Jung Lee for the judgment.

${ }^{10}$ I thank Heejeong Ko for bringing this to my attention.

11 Thanks to Hiroshi Mito for suggesting example (25).
} 


\section{Sumiyo Nishiguchi}

(24) Ko-no saifu-mo \#(zenzen/amari) tsukawa-nakat-ta. this-GEN wallet-also at all/much use-NEG-PAST 'I have not used this wallet at all/much.'
a. Kare-mo kekkon-seikatsu-mo umaku ika-nakat-ta-ne. he-also marriage-life-also well go-NEG-PAST-PAR 'His married life did not go well, did it?'
b. Kono hon-mo yoku wakara-nakat-ta-ne. this book-also well can.understand-NEG-PAST-PAR 'This book was also hard to understand, wasn't it?'
c. Ano baito-mo tsukae-nakat-ta. that part-time-worker-also can.use-NEG-PAST 'That part-time worker was not usable, either.'

(24) seems to suggest that the negation that anti-licenses the BPI licenses the NPI zenzen/amari, so that it no longer anti-licenses the BPI. In (25), the presence of non-monotonic modal-like elements licenses the illegitimate clausemate BPI.

\section{BPI Licensing Contexts}

BPI licensers are either monotone decreasing, anti-additive, extra-clausal antimorphic negation, or non-monotonic explicit/implicit emotives; therefore, BPI licensing contexts can be summarized as in (26). The distribution of polarity items including the BPIs coincides with the feature inheritance hierarchy, which is not bound (cf. Carpenter 1992) in (27).
a. [MD...BPI...]
b. [AA...BPI...]
c. $\mathrm{NEG}_{\text {antimorphic }}[\mathrm{CP} . . . \mathrm{BPI} \ldots .$.
d. $*\left[\mathrm{NEG}_{\text {antimorphic...BPI... }]}\right.$
e. PRED emotive $_{\text {CP...BPI... }]}$
f. $\pm\left(\right.$ PRED $\left._{\text {emotive }}\right)[$ [CP...BPI...]
g. \pm PRED $_{\text {emotive }}[$ CP....BPI...]

(Japanese, Korean, Chinese)

h. - PRED $_{\text {emotive }}[\mathrm{CP} \ldots$ BPI...]

(Serbo-Croatian, Japanese, Korean, Chinese)

(MD: monotone decreasing, AA: anti-additive, PRED: predicate, + : positive, - : negative, ( ): implicit)

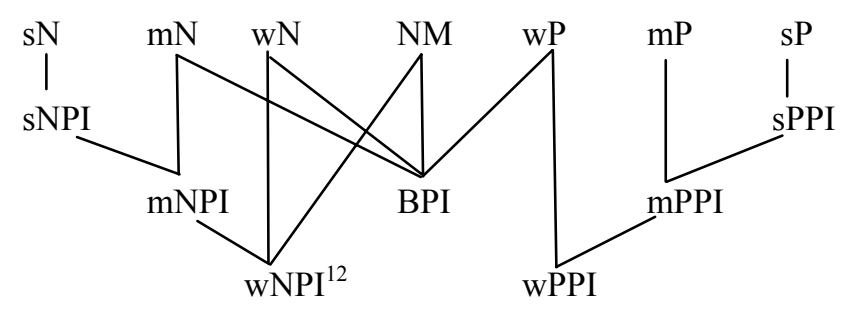

${ }^{12}$ Weak NPIs such as any and ever can appear in non-monotonic scope (Nishiguchi 2003, 2004). 


\section{Bipolar Items and Attitude Predicates}

The distributions of BPIs can be explained by the feature checking mechanism. As Bernardi (2002) incorporates NPI licensing relations and monotonic properties into a lexical entry in Categorial Type Logic, the BPI is assigned the feature $[\mathrm{mN} \sqcap \mathrm{wN} \sqcap \mathrm{NM} \sqcap \mathrm{wP}]$, which is the meet of medium negative $(\mathrm{mN})$, weak negative $(\mathrm{wN})$, nonmonotone $(\mathrm{NM})$, and weak positive $(\mathrm{wP})$ in the notation of combinatory categorial grammar (Steedman 2000, among others). The BPI feature can be checked in the $\mathrm{wN}, \mathrm{NM}$, or medium negative [ $\mathrm{wN} \sqcap \mathrm{mN}$ ] context; for example, a Hungarian monotone decreasing determiner kevés 'few' returns a quantifier that selects VP with the BPI feature, as shown in (29). However, the BPI feature cannot be checked with the strong negative $[\mathrm{sN} \sqcap \mathrm{mN} \sqcap \mathrm{wN}] .{ }^{13}$

(28) Lexical entry:

BPI

non-monotonic emotive

weak negation

medium negation

strong negation
NP-also: $\mathrm{S}_{[\mathrm{mN} \sqcap \mathrm{wN} \sqcap \mathrm{NM} \sqcap \mathrm{wP}]} /(\mathrm{NP} \backslash \mathrm{S})$;

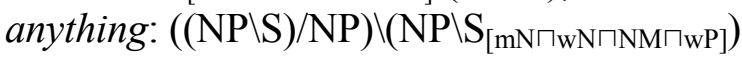

regret: $(\mathrm{NP} \backslash \mathrm{S}) / \mathrm{S}_{[\mathrm{mN} \sqcap \mathrm{wN} \sqcap \mathrm{NM} \sqcap \mathrm{wP}]}$

few: $\left(\mathrm{S} /\left(\mathrm{NP} \backslash \mathrm{S}_{\mathrm{wN}}\right)\right) / \mathrm{NP}$

none: $\left(\mathrm{S} /\left(\mathrm{NP} \backslash \mathrm{S}_{\mathrm{mN} \sqcap \mathrm{wN}}\right)\right) / \mathrm{NP}$

not: $\left(\mathrm{NP} \backslash \mathrm{S}_{\mathrm{SN} \sqcap \mathrm{mN} \sqcap \mathrm{wN}}\right) /(\mathrm{NP} \backslash \mathrm{S})$

$$
\begin{array}{llll}
\begin{array}{l}
\text { Kevés } \\
\text { 'few' }
\end{array} & \begin{array}{l}
\text { ember } \\
\text { 'people' }
\end{array} & \begin{array}{l}
\text { értett } \\
\text { 'understood' }
\end{array} & \begin{array}{l}
\text { valamit is } \\
\text { 'anything' }
\end{array} \\
\hline:\left(\mathrm{S} /\left(\mathrm{NP} \backslash \mathrm{S}_{\mathrm{wN}}\right)\right) / \mathrm{NP} & : \mathrm{NP} & :(\mathrm{NP} \backslash \mathrm{S}) / \mathrm{NP} & \begin{array}{l}
:(\mathrm{NP} \backslash \mathrm{S}) / \mathrm{NP}) \backslash \\
\end{array} \\
& & \left(\mathrm{NP} \backslash \mathrm{S}_{[\mathrm{mN} \sqcap \mathrm{wN} \sqcap \mathrm{NM} \sqcap \mathrm{wP}]}\right)
\end{array}
$$

Laka (1994) assumes that negative predicates such as deny and doubt select a negative complementizer with [+neg], which licenses NPIs in embedded clauses.

a. The witnesses denied that anybody left the room before dinner.

b. *The witnesses denied anything.

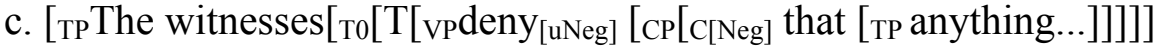

Applying Laka's theory, we assume that emotives select S with the BPI feature in (31).

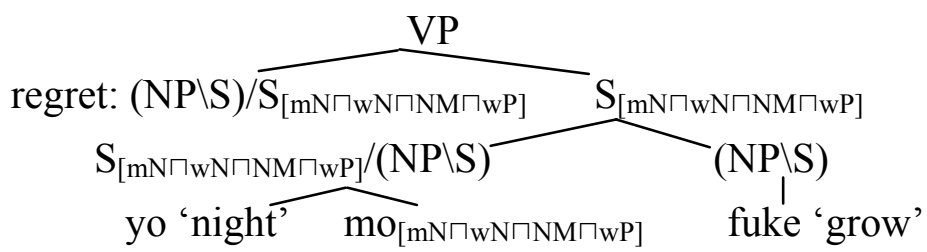

The BPI returns $\mathrm{S}$ with the $[\mathrm{mN} \sqcap \mathrm{wN} \sqcap \mathrm{NM} \sqcap \mathrm{wP}]$ feature when composing with the predicate. Then, the $\mathrm{S}$ with the BPI feature combines with non-monotonic

\footnotetext{
${ }^{13}$ My thanks to Raffaella Bernardi for the discussion.
} 


\section{Sumiyo Nishiguchi}

emotives that select $\mathrm{S}$ with the BPI feature. On the other hand, the negative predicate in the matrix clause also selects $\mathrm{S}$ with the BPI feature, as in (32).

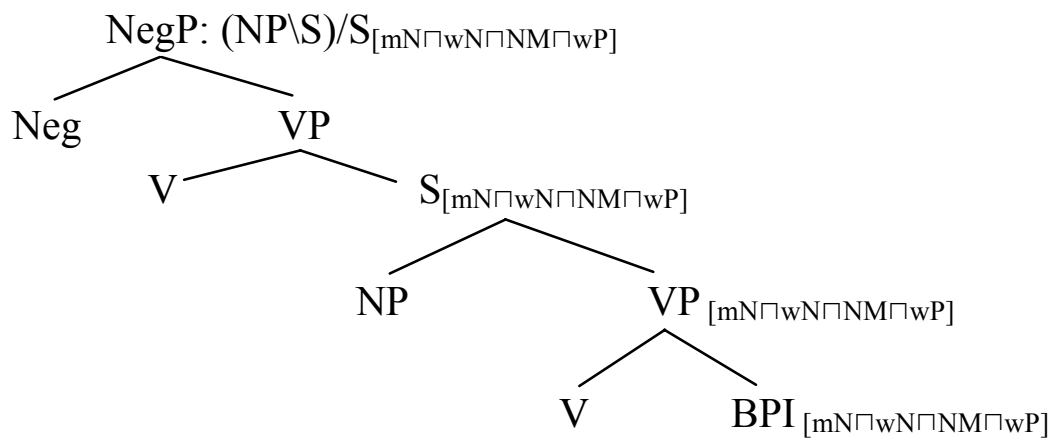

\section{Conclusion}

This article discussed BPIs which share the features of both NPIs and PPIs. As NPIs, BPIs are licensed in anti-additive or monotone decreasing contexts. As PPIs, BPIs are ungrammatical with clausemate negation. BPIs are licensed by extra-clausal explicit or implicit non-monotonic factive emotives as well as superordinate negation. Adding an NPI rescues BPIs in clausemate negation.

\section{References}

Aronoff, Mark. 1976. Word formation in generative grammar. Cambridge, MA: MIT Press.

Asher, Nicholas. 1987. A typology for attitude verbs and their anaphoric properties. Linguistics and Philosophy 10:125-197.

Baker, Carl L. 1970. Double negatives. Linguistic Inquiry 1:169-186.

Bernardi, Raffaella. 2002. Reasoning with polarity in categorial type logic. Ph.D. diss., Utrecht University.

Carpenter, Bob. 1992. The logic of typed feature structures: With applications to unification grammars, logic programs and constraint resolution. Cambridge: Cambridge University Press.

Fauconnier, Gilles. 1975a. Polarity and the scale principle. In R.E. Grossman, L. J. San, and T.J. Vance, eds., Papers from the Eleventh Regional Meeting of the Chicago Linguistic Society, 188-199. Chicago: Chicago Linguistic Society.

Fauconnier, Gilles. 1975b. Pragmatic scales and logical structure. Linguistic Inquiry 6:353-375.

von Fintel, Kai. 1999. NPI licensing, Strawson entailment, and context dependency. Journal of Semantics 16:97-148.

Heim, Irene. 1992. Presupposition projection and the semantics of attitude verbs. Journal of Semantics 9:183-221.

Hoeksema, Jack. 1998. On the (non)loss of polarity sensitivity. In Historical linguistics 1995, vol. 2, Germanic linguistics, 101-114. Amsterdam: John Benjamins. 


\section{Bipolar Items and Attitude Predicates}

Kato, Yasuhiko. 1985. Negative sentences in Japanese. Sophia Linguistica 14:1-229.

Kato, Yasuhiko. 2000. Interpretive asymmetries of negation. In Negation and polarity: Syntactic and semantic perspectives, 62-87. Oxford: Oxford University Press.

Ladusaw, William. A. 1979. Polarity sensitivity as inherent scope relations, Ph.D. diss., University of Texas, Austin.

Laka, Itziar. 1990. On the syntax of negation. Ph.D. diss., MIT.

Lambrecht, Knud. 1994. Information structure and sentence form. Cambridge: Cambridge University Press.

Nam, Seungho. 1994. Another type of negative polarity item. In Dynamics, polarity, and quantification, 3-15. Stanford: CSLI.

Nishiguchi, Sumiyo. 2003. Non-monotonic negativity. In D. H. Ji et al., eds., Proceedings of PACLIC 17, 204-215. Singapore: COLIPS.

Nishiguchi, Sumiyo. 2004. Five types of affective contexts: Nonmonotonic NPI licensers. In N. Adams et al., eds., CLS 40-1: The main session. Papers from the 40 ${ }^{\text {th }}$ Meeting of the Chicago Linguistic Society, 249-264. Chicago: Chicago Linguistic Society.

Numata, Yoshiko. 2000. Toritate (focus). In S. Kinsui et al., eds., Toki, hitei to toritate, 151-216. Tokyo: Iwanami.

Progovac, Ljiljana. 1994. Negative and positive polarity: A binding approach. Cambridge: Cambridge University Press.

Sadanobu, Toshiyuki. 1997. Shinteki prosesu kara mita toritateshi te, demo, nihongo no shudai to toritate, 227-260. Tokyo: Kuroshio.

Steedman, Mark. 2000. The syntactic process. Cambridge: MIT Press.

Szabolcsi, Anna. 2002. Hungarian disjunctions and positive polarity. In I. Kenesei and P. Siptár, eds., Approaches to Hungarian, vol. 8, 217-241. Budapest: Akadémiai Kiadó.

van der Wouden, Ton. 1997. Negative contexts: Collocation, polarity and multiple negation. London: Routledge.

Watanabe, Akira. 2004. The genesis of negative concord: Syntax and morphology of Negative Doubling. Linguistic Inquiry 35:559-612.

Zwarts, Frans. 1996. A hierarchy of negative expressions. In H. Wansing, ed., Negation: A notion in focus, 169-194. Berlin: Walter de Gruyer.

Zwarts, Frans. 1997. Three types of polarity. In F. Hamm and E. Hinrichs, eds., Plurality and quantification, 177-238. Dordrecht: Kluwer Academic.

Sumiyo Nishiguchi

Osaka University

Graduate School of Language and Culture

1-8 Machikanaeyama

Toyonaka, Osaka 560-0043

Japan

u301192b@ecs.cmc.osaka-u.ac.jp 